\title{
PENDAMPINGAN ONLINE DALAM JARINGAN (DARING) SERTIFIKASI KOMPETENSI TENAGA KERJA KONSTRUKSI PADA MASA PANDEMI COVID-19 DI PROVINSI LAMPUNG
}

\author{
Fery Hendi Jaya ${ }^{1}$, Sari Utama Dewi ${ }^{2}$, M.Fikri Akbar ${ }^{3}$ \\ Fakultas Teknik, Prodi Teknik Sipil Universitas Sang Bumi Ruwa Jurai \\ feryhjaya@gmail.com,
}

\begin{abstract}
abstrak
Kompetensi tenaga kerja kontrusi sadah semakin berkembag dengan ditetapkannya kebijakan. peningkatan kualitas dan kuantitas sertifikasi kompetensi tenaga kerja memang sangat penting serta membutuhkan pelaksanaan sertifikasi yang benar-benar objektif, tepat tujuan, sasaran, akuntabilitas dan bermanfaat baik secara teknis maupun administratif. Permasalahannya yaitu kurangnya informasi, minimnya pengetahuan lemahnya daya tarik dan kurangnya pembinaan serta pendampingan. Metode yang digunakan dalam pelaksanaan yaitu metode standarisai kompetensi tenaga kontruksi. Langkah yang dilakukan yaitu tahap persiapan, tahap pengguanan perangkat, tahap evaluasi. Dari pelaksaan dapat disimpulkan 1). peningkatan sumber daya manusia (SDM) terutama pengetahuan praktis konstruksi berbasis informasi dan data internet (Daring) kepada peserta, dimasa pandemik covid-19 ini (Mahasiswa / SMK, Pekerja Konstruksi, masyarakat,tukang dan mandor) uji kompetensi tenaga kerja konstruksi di random pada kabupaten/kota di propinsi Lampung. 2) Membantu masyarakat konstruksi untuk dapat lebih efektif (lulus uji) dan sadar akan kebutuhan sertifikasi kompetensi tenaga kerja sesuai dengan amanat UU No.2 Tahun 2017 tentang Jasa Konstruksi terkhusus di propinsi Lampung.3) Membantu kinerja pemerintah dalam hal ini Balai Besar Pembinaan Jasa Konstruksi Wilayah Sumatera Bagian Selatan dan LPJK Daerah Lampung dalam percepatan kualitas dan kuantitas Kompetensi Tenaga Kerja Konstruksi.
\end{abstract}

Kata Kunci : Pendampingan Online, Sertifikasi Kompetensi Tenaga Kerja, Covid-19

\begin{abstract}
The competency of the hard contribu- tion workforce is increasingly developing with policy policies. quality improvement and labor competency certification are indeed very important and require implementation that is truly objective, right on target, accountable and beneficial both technically and administratively. The mistakes are lack of information, lack of attractiveness and lack of guidance and assistance. The method used in implementing the standardized method of construction staff competence. The steps taken are the preparation stage, the device use stage, the evaluation stage. From implementation it can be rejected 1). increase in human resources (HR), especially practical knowledge of construction based on information and internet data (Brave) to participants, during the Covid-19 pandemic (Students / Vocational Schools, Construction Workers, communities, builders and foremen), the competency test for construction workers is random at regencies / cities in Lampung province. 2) Helping the construction community to be more effective (passing the test) and aware of the need for labor certification in accordance with the mandate of Law No.2 of 2017 concerning Construction Services, especially in Lampung province. 3) Assisting the performance of the government in this case the Center for Construction Services Development Southern Sumatra Region and Lampung Regional LPJK in accelerating the quality and quantity of construction workforce competencies.
\end{abstract}

Keywords : Online Assistance, Manpower Competency Certification, Covid-19

\section{PENDAHULUAN}

Sesuai dengan amanat Undang-undang Jasa Konstruksi No.2 tahun 2017 tentang Jasa Konsruksi yang telah diperbaharui yakni memberikan arah pertumbuhan dan perkembangan 
jasa konstruksi dengan mewujudkan struktur usaha yang kokoh, handal, berdaya saing tinggi, serta menghasilkan jasa konstruksi yang berkualitas serta mewujudkan penyelenggaraan jasa konstruksi yang menjamin kesetaraan kedudukan pengguna dan penyedia jasa, dan terpenting dapat terciptanya peningkatan partisipasi masyarakat dibidang jasa konstruksi, sesuai amanat UU Jasa Konstruksi Bab X teruju pasal 84 s.d pasal 87 yang telah diperbaharui.

Lingkup pembinaan bidang jasa konstruksi oleh Pemerintah Pusat, sesuai UU Jasa Konstruksi saat ini sudah semakin berkembang dengan ditetapkannya kebijakan, pengawasan dan pemantauan serta pengembangan kerjasama desentralisasi dengan melibatkan pemda/pemprov, masyarakat, lembaga perguruan tinggi, stakeholder dan asosiasi profesi jasa konstruksi di Indonesia. Sebagai wakil pemerintah pusat, Gubernur memiliki kewenangan dalam melakukan pengawasan dan pembinaan melalui pelatihan,

Pelaksanaan sertifikasi kompetensi baik berupa sertifikasi keterampilan (SKT) dan sertifikasi keahlian (SKA) bagi tenaga kerja teknik yang terakreditasi pada Lembaga Pengembangan Jasa Konstruksi Nasional (LPJKN) menjadi kebutuhan standar mutu dan legislasi penilaian bagi personil suatu perusahan konstruksi yang ada di Indonesia mulai dari tingkat keterampilan dan keahlian profesional oleh pihak yang berkompeten yang independen. Sertifikasi keterampilan dan keahlian diartikan sebagai upaya pemerintah untuk menstandarisasi dan menjamin mutu tenaga terampil dan profesional dibidang konstruksi rancang-bangun, sehingga lebih mudah mengikuti pada tahapan pendidikan selanjutnya.

Sertifikasi kompetensi kerja merupakan proses uji kompetensi yang sesuai dengan standar kompetensi kerja nasional maupun internasional yang memiliki standar khusus, berupa evaluasi dan penilaian secara komprehensif atas komitmen Asosiasi Jasa Konstruksi dan lembaga pendidikan terhadap kualitas serta kapasitas (skill, knowlage, etika) personal peserta, untuk menentukan kemampuan dan kelayakan tenaga teknis di suatu proyek konstruksi. Dimana masing-masing personal diharapkan mampu melakukan suatu perencanaan, pelaksanaan, pengawasan sampai dengan evaluasi pekerjaan konstruksi.

Penilaian harus dilakukan dengan standar baku dan sesuai jenjang tingkatan agar penilaian memiliki standar yang sama. Sertifikasi menjadi hal penting untuk menetapkan posisi sesuai bidang keterampilan dan keahlian, baik struktur komposisi personal didalam persaingan global pekerjaan proyek konstruksi di indonesia maupun mancanegara.

Oleh karena itu, peningkatan kualitas dan kuantitas sertifikasi kompetensi tenaga kerja memang sangat penting serta membutuhkan pelaksanaan sertifikasi yang benar-benar objektif, tepat tujuan, sasaran, akuntabilitas dan bermanfaat baik secara teknis maupun administratif. Sasaran lainya sertifikasi kompetensi tenaga kerja juga bisa memberikan kontribusi manfaat pada semua pihak, baik pemerintah, asosiasi jasa konsruksi, lembaga pendidikan, terlebih calon peserta sertifikasi kompetensi tenaga kerja. Melalui sertifikasi kompetensi tenaga kerja, pemerintah dan lembaga penegembangan jasa konstruksi yang menaungi seluruh asosiasi profesi teknik bisa lebih mudah menjamin mutu dan menjaga nilai profesionalitas personal dan lembaga.

Pada tahapan implementasinya baik bentuk pelatihan kompetensi dan asesmen calon sertifikasi kompetensi tenaga kerja, saat ini telah dipayungi dengan peraturan dan ketetapan menggunakan program berbasis online. Dan harus melaksanakan beberapa tahapan sesuai dengan standar kreteria sub bidang yang akan diperoleh oleh calon sertifikasi kompetensi tenaga kerja. Terpenting dalam proses ini adalah keberadaan serta peran serta instruktur dan asesor kompetensi tenaga kerja yang telah teregister di Lembaga Jasa Konstruksi Daerah (LPJK D) provinsi Lampung dan LPJK Nasional Republik Indonesia.

\section{Permasalahan Jumlah Sertifikasi Kompetensi Tenaga Kerja Konstruksi}


Kebutuhan tenaga terampil dan ahli sesuai dengan sub bidang konstruksi yang memiliki sertifikat kompetensi di Indonesia, hingga tahun 2019 dari 5,3 juta orang baru 9,67\% tenaga kerja yg bersertifikat. Dan yang aktif hanya 573.211 orang memiliki setifikat terampil serta 247.674 orang memiliki serifikat ahli. Dari jumlah itu sangatlah kurang dari kuota yang diharapkan oleh pemerintah pusat. Sedangkan ini telah diamanatkan oleh UU No.2 Tahun 2017 tentang Jasa Konstruksi. Pemerintah Pusat dalam hal ini melalui Kementrian Pekerjaan Umum (Balai Besar Bina Jasa Konstruksi) dan LPJK Nasional Indonesia telah mengeluarkan Surat Edaran Mentri (SE) No.02/03 Tahun 2016 tentang Percepatan Setrifikasi Kompetensi Tenaga Konstruksi untuk LPJK Daerah Provinsi Lampung, guna memacu jumlah dan kualitas pemegang sertifikat kompetensi tenaga kerja konstruksi.

Menurut informasi data LPJK D Provinsi Lampung yang terhimpun pada 3 (tiga) tahun terakhir jumlah sertifikat kompetensi tenaga kerja konstruksi di provinsi lampung sampai dengan penghujung tahun 2019 membutuhkan kuota sertifikat terampil sebanyak 20.000 orang, sedangkan yang teregister hanya 4400 orang, begitu halnya dengan tenaga ahli konstruksi membutuhkan kuota sertifikat Ahli sebanyak 5000 orang, namun baru teregister sebesar 700 orang saja.

Dari hasil identifikasi dan analisis terhadap permasalahan yang dihadapi dan harus dipecahkan solusi yang terbaik oleh "Team Pendamping", sebagai berikut :

1. Kurangnya informasi dan sosialisasi terhadap UU No.2 Tahun 2017 serta aturan dibawahnya tentang Jasa Konstruksi , kepada para tenaga kerja konstruksi yang bernaung dalam asosiasi profesi konstruksi di provinsi Lampung.

2. Minimnya pengetahuan, kemampuan dan etika sesuai standarisasi kompetensi sub bidang konstruksi oleh para tenaga kerja konstruksi di provinsi Lampung.

3. Lemahnya daya tarik dan keinginan para tenaga kerja konstruksi untuk memiliki kewajiban sertifikasi kompetensi tenaga kerja di provinsi Lampung.

4. Kurangnya pembinaan dan pendampingan secara kontinyu baik berupa pelatihan-pelatihan dan workshop untuk tenaga kerja konstruksi, baik melalui instansi,lembaga dan institusi perguruan tinggi di provinsi Lampung.

\section{METODE PELAKSANAAN}

Metode pelaksanaan pendampingan sertifikasi yang akan tempuh yakni dengan menerapkan konsep teori administrasi berbasis online dan praktik dalam jaringan (Daring) sesuai sub bidang ilmu kompetensi tenaga kerja konstruksi, sebagai berikut :

\section{Prosedur Data Administrasi Berbasis Online}

Dengan dikeluarkannya UU dan aturan yang mengikat tentang sertifikasi kompetensi tenaga kerja konstruksi berbasis online, maka langkah pendampingan sebagai berikut :

1. Tahap Persiapan berkas personal calon sertifikasi kompetensi tenaga kerja konstruksi, sesuai standar kreteria yang baku.

2. Tahap penggunaan perangkat PC/Laptop sesuai dengan kreteria tahapan berbasis data online.

3. Tahap evaluasi dan supervisi data online personal kompetensi, menggunakan aplikasi Blue Jeans.

\section{Metode Standarisasi Kompetensi Tenaga Kerja Konstruksi.}

Untuk lebih mendapatkan keakurasian pelaksanaan metode standarisasi sertifikasi kompetensi dititik beratkan pada pelaksanaan sebagai berikut : 
1. Pelatihan informasi dan sosialisasi peraturan perundangan kompetensi tenaga kerja konstruksi terkini.

2. Pelatihan pengetahuan (knowlage) sub bidang tenaga kerja konstruksi.

3. Pelatihan kemampuan dasar (soft skill) sub bidang tenaga kerja konstruksi.

4. Pelatihan etika profesi (professional ethics) sub bidang tenaga kerja konstruksi.

5. Pada point 1-4 serta Pendampingan dan konsultasi, berbasis aplikasi online.

\section{Spesifikasi Rancangan Kegiatan}

Daya dukung pelaksanaan spesifikasi rancangan ini sangatlah mutlak dan dapat terealisasi sesuai dengan harapan bersama jika dibuatkannya network planning atau rancangan jadwal tahapan kegiatan, yang berisikan administrasi; durasi waktu, biaya, dan mutu capaian baik dalam segi perencanaan, pengawasan, pelaksanaan dan evaluasi personal peserta sertifikasi kompetensi tenaga kerja konstruksi di provinsi Lampung.

\section{Partisipasi Mitra Dalam Pelaksanaan Sertifikasi Kompetensi}

Partisipasi kemitraan dalam pelaksanaan pendampingan peserta sertifikasi kompetensi tenaga kerja konstruksi ini tidaklah dapat tercapai dengan baik dan sempurna jika pihak-pihak stakeholder, pemerintah (kementrian PUPR Indonesia), Balai Besar Pembinaan Jasa Konstruksi Wilayah Palembang, lembaga pengembangan jasa konstruksi, perguruan tinggi, asosiasi profesi konstruksi dan masyarakat harus terlibat secara kontinyu. Dengan demikian langkah konkrit yang dilaksanakan berupa Memorandum Of Understanding (MOU) kepada pihak-pihak yang terkait dan terlibat dalam pelaksanaan sertifikasi kompetensi tenaga kerja konstruksi guna tercapainya profesionalitas dan akuntabilitas program yang baik ini.

\section{Jenis Luaran Yang dihasilkan}

Program pendampingan ini sangatlah diharapkan oleh semua pihak dan memiliki luaran sebagai berikut :

1. Publikasi Internal dan eksternal, kepada masyarakat jasa konstruksi di propinsi Lampung.

2. Jurnal Ilmiah Dosen, yang teregistrasi standar akreditasi nasional dan mudah diakses.

3. Menjalankan amanat UU No.2 Tahun 2017 Tentang Jasa Konstruksi, serta pemantapan dan sumbangsih kewajiban masyarakat konstruksi terhadap kuantitas dan kualitas sertifikasi kompetensi tenaga kerja konstruksi di provinsi Lampung berbentuk sertifikat Keterampilan.

4. Sebagai bentuk sumbangsih pengabdian lembaga perguruan tinggi di bidang rancangbangun konstruksi di Indonesia terkhusus di provinsi Lampung.

5. Peningkatan SDM dan Implementasi kegiatan dimasa pandemic covid-19 menggunakan jaringan internet (Daring) dan beberapa aplikasi yang digunakan.

\section{HASIL DAN LUARAN YANG DICAPAI}

\section{Hasil Yang Dicapai}

Adapun hasil pelaksanaan kegiatan yang dilaksanakan berupa Foto kegiatan : 

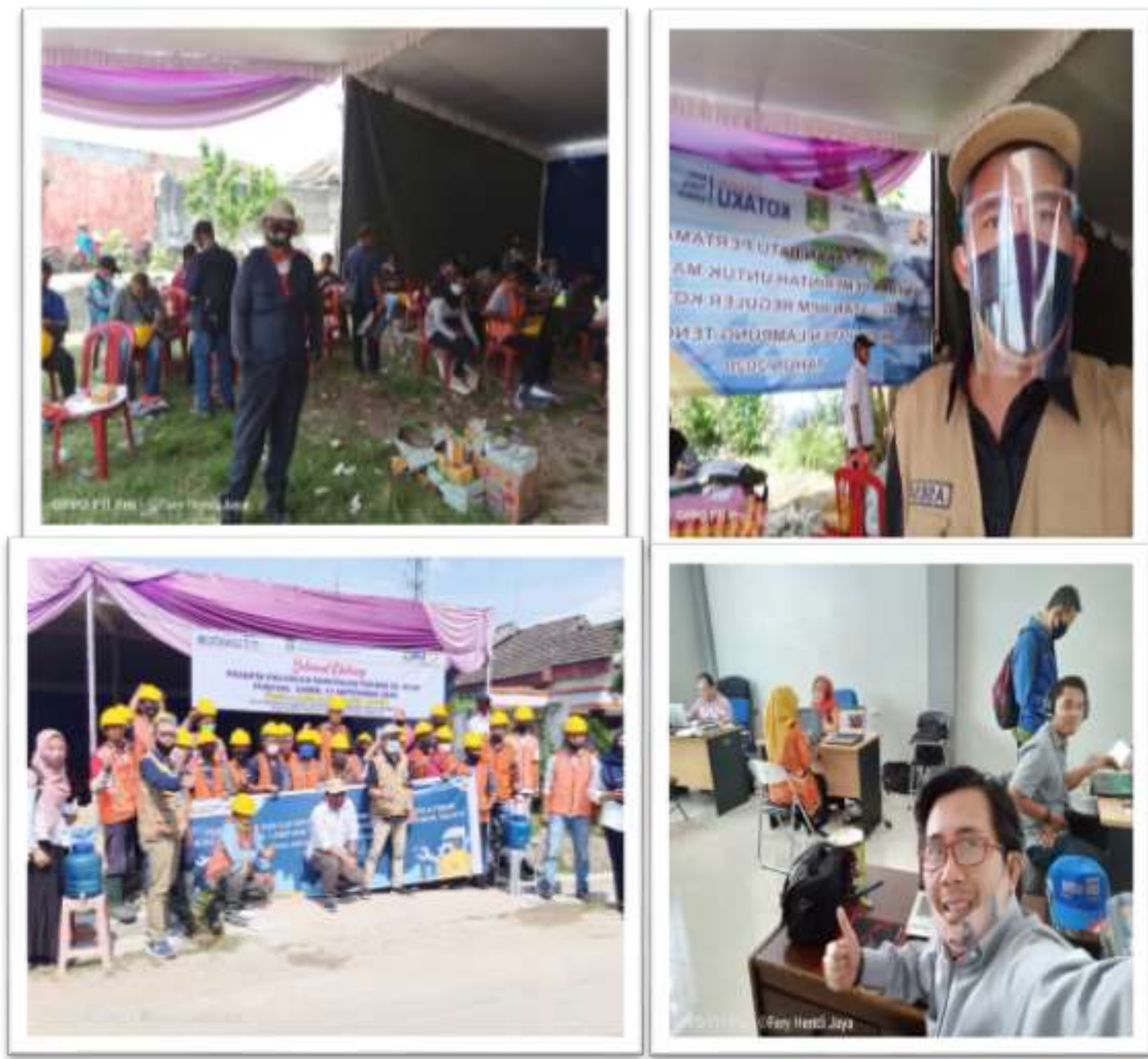

(Dokumentasi Pelaksanaan Pendampingan, ada pada lampiran ini.)

\section{Luaran Yang Dicapai}

Luaran yang akan dicapai yakni berbentuk :

1. Publikasi internal yakni poto-poto dokumentasi kegiatan yang dilakukan, dan eksternal berupa publikasi di media cetak dan onine serta youtobe.

2. Jurnal Ilmiah Dosen, yang dapat diakses dan terintegrasi dengan sister pangkalan dikti.

3. Sertifikat Kompetensi berbentuk hard copy dan digital, bagi para peserta uji kompetensi tenaga kerja sesuai bidang keahlian yang diikuti.

Catatan : poin 1-3 bentuk pisik dan dokumen pada lampiran ini

\section{KESIMPULAN DAN SARAN}

\section{Kesimpulan}

Dalam pelaksanaan kegiatan Pengabdian kepada masyarakat ini dapat disimpulkan beberapa hal terpenting sebagai berikut :

1. Peningkatan sumber daya manusia (SDM) terutama pengetahuan praktis konstruksi berbasis informasi dan data internet (Daring) kepada peserta, dimasa pandemik covid-19 ini (Mahasiswa / SMK, Pekerja Konstruksi, masyarakat,tukang dan mandor) uji kompetensi tenaga kerja konstruksi di random pada kabupaten/kota di propinsi Lampung. 
2. Membantu masyarakat konstruksi untuk dapat lebih efektif (lulus uji) dan sadar akan kebutuhan sertifikasi kompetensi tenaga kerja sesuai dengan amanat UU No.2 Tahun 2017 tentang Jasa Konstruksi terkhusus di propinsi Lampung.

3. Membantu kinerja pemerintah dalam hal ini Balai Besar Pembinaan Jasa Konstruksi Wilayah Sumatera Bagian Selatan dan LPJK Daerah Lampung dalam percepatan kualitas dan kuantitas Kompetensi Tenaga Kerja Konstruksi.

\section{Saran}

Adapun saran yang perlu dipertimbangkan dan direalisasikan kedepan yakni :

1. Pemerintah dalam hal ini Balai Besar Jakon-Palembang dan mitra USTK-Lpjk Daerah Lampung dapat lebih memaksimalkan kuota dan jumlah peserta uji kompetensi di 15 (lima belas) kabupaten/kota se-propinsi lampung agar apa yang diamanatkan oleh Undangundang bisa terwujud dan merata sampai pelosok daerah, walaupun masih terdampak wabah covid-19.

2. Perlu dilakukan Bimtek dan pelatihan serupa sesuai bidang keahlian/keterampilan dengan jadwal waktu yang cukup agar dapat menghasilkan nilai tambah bagi peserta serta kualifikasi SDM yang handal serta kompeten di bidangnya, menggunakan aplikasi dan sarana internet (kuota) yang memadai dan di dukung oleh perangkat yang siap digunakan dalam jaringan internet.

3. Dengan adanya percepatan kegiatan uji kompetensi bagi tenaga kerja konstruksi diharapkan proses bentuk sertifikat dapat diberikan kepada peserta secara cepat dan langsung dapat digunakan oleh peserta.

\section{DAFTAR PUSTAKA}

Anjani, F. (2017). Pengaruh Kompetensi Terhadap Kinerja Karyawan Dengan Motivasi Sebagai Variabel Moderator di PT Telekomunikasi Regional III area Witel Bandung

Muhammad Saroni.(2017).Sertifikasi Keahlian Siswa. Yogyakarta:Ar-Ruzz Media.

Peraturan Badan Nasional Sertifikasi Profesi Nomor : 1/BNSP/III/2014 Tentang Pedoman Penilaian Kesesuaian - Persyaratan Umum Lembaga Sertifikasi Profesi.

Putri, F. A., Yoto, Y., \& Sunarto, Y.(2017). Studi Pengelolaan Pelaksanaan Uji Kompetensi Keahlian di SMK PGRI 3 Malang. Jurnal Pendidikan Profesional, 6(2).

Setyowati, W.(2017). "Pembentukan Lembaga Sertifikasi Profesi (LSP) Sebagai Sarana Peningkatan Sumber Daya Manusia Kompeten”. Jurnal Penamas, 1(1). 